\title{
9. Sorcery, Poison and Politics: Strategies of Self-Positioning in South Malekula, Vanuatu
}

\author{
Laurent Dousset
}

Sorcery and (black) magic are far from being limited to non-Western worlds. In the industrialised world there has also been a recrudescence in beliefs and practices that relate to a supernatural world, state of consciousness or capacity to act, often labelled 'modern occultism'. ${ }^{1}$ Taking for granted that researchers agree on the definition of sorcery - a problem whose answer is far from obvious - we must, however, admit that the study of these widespread phenomena is subjected to differing and sometimes conflicting layers of analyses summarised by two general perspectives. The first integrates these beliefs and practices into their local historical, material and social contexts of emergence and persistence. Here sorcery is seen as the consequence - and less frequently the cause of disruptive social conditions. Because this perspective does not account for the widespread existence of sorcery, the second perspective concedes sorcery a place among all those phenomena that seem to be inherently human and are suggestive of universalism. The former approach is peculiar to ethnography and cultural or legal studies and is occasionally tinged with what could be called 'scientific moralism' in that sorcery is depicted in terms of notions such as crisis, disruption or stress. The latter finds adepts among psychoanalysts and philosophers - and, to some extent, anthropologists - and occasionally espouses a degree of ethnocentrism, because it is a difficult task to develop a generally applicable explanation without including a particular perspective, at least that of the analyst. Rarely, however, are these perspectives combined, and too often they remain echoes of conflicting points of (world) view and epistemologies rather than integrated analyses.

Delpech-Ramey's paper is a good example illustrating the opposition of worldviews the two approaches embody:

For Adorno, any contemporary fascination with the occult must be read as a symptom of the deadlock of the Enlightenment. Such a fascination indicates ... the failure of Enlightenment to liberate us fully from magic and is a sign of the ongoing crisis caused by that incomplete liberation. (Delpech-Ramey 2010:9)

1 See, for example, Owen (2004). 
Sorcery and liberation from it are, for Adorno (2005), the consequences of unfinished historical processes. Delpech-Ramey, espousing the second perspective mentioned above, therefore rejects the latter's conclusions and turns to the more universalistic explanations of Deleuze and Guattari (1983, 1987). Because identities and collectivities are inherently relational and constantly in a 'state of becoming', they cannot be 'the subject of straightforward modes of representation, whether in ontological or political discourse' (DelpechRamey 2010:10). 'What Deleuze and Guattari see in the sorcerer', DepecheRamey (2010:13) continues, "is a particularly condensed ability to "go beyond" the normal place of development'. In other words, sorcery is a place where boundaries become permeable and where institutions are restructured, where distinctions such as that between animality and humanity become precarious for a reconfiguration of human and social institutions.

Not only do Deleuze and Guattari discuss sorcery specifically in connection with problems of group formation and trans-individual processes; Deleuze's earliest writings on occult themes also show that, at least in his mind, esoteric insights and occult powers are not ultimately the tools of the renegade or the means of escape from the perplexities of human institutions, but in fact have their ultimate significance precisely in the creative rehabilitation of political institutions. (Delpech-Ramey 2010:16; emphasis added)

The mention of Delpech-Ramey, Adorno, Deleuze and Guattari is of course not fortuitous here since, once their positions are combined, they reflect the perspective developed in this chapter. Following Adorno and others, sorcery in Melanesia and in particular Vanuatu will be considered as the consequence of specific historical conditions. But it will also be understood as a universal means of shifting borders and differences when institutions and representations are questioned.

Anthropologists have on many occasions attempted to combine the observation that sorcery is a widespread phenomenon across many societies with the analysis of its local and historical conditions of emergence. The papers in the volume edited by Zelenietz and Lindenbaum (1981), for example, illustrate how closely sorcery is tied to the general problem of 'power' and to the transformations it undergoes in particular contexts. Sorcery and the presumed recrudescence of it in Melanesia, as Lindenbaum (1981:119) told us in the early 1980s, is best tackled through an anthropology of legitimacy and control. Such an approach could combine the analysis of the general spectrum of sorcery and of its particularistic manifestations (e.g. Zelenietz 1981).

Here I would like to further explore this anthropology of legitimacy and attempt to combine it with Deleuze and Guattari's $(1983,1987)$ suggestion that 
sorcery embodies the permeability of constant becoming and changing. Despite the distressing situations sorcery often engenders in communities, my aim is to escape the scientific moralism mentioned above and engage local ethnography in more general and constructive considerations. I suggest that sorcery is a place where belonging and being are reconfigured and therefore where notions of the 'person', the 'group', 'ethnicity' or 'power' are redefined and adapted to changing historical and material conditions. I thus consider that the particular local conditions trigger and frame the processes of social reconfiguration, but that it is in and through sorcery that the cognitive and social schema of such change can take place, because sorcery is inherently a means of shifting borders. The supernatural points to a not-yet-redefined humanity, and sorcery is a vehicle through which the uncertain contours of humanity are simultaneously expressed and resolved. These hypotheses will be illustrated using the ethnography of recent sorcery accusations in the south of Malekula, one of the main islands in the archipelago of Vanuatu.

\section{An ethnographic account}

Let me start with an ethnographic case recorded in 2011 in Vanuatu. Explanations of the social and historical background will follow after the account. A few years ago, when John came back to his village on Malekula Island after living in Port Vila, the capital, for a few years, he claims he became the victim of sorcery attempts. Two elderly men, close brothers of a politically important chief from a nearby hamlet, were the primary suspects. 'Two men', John says, 'who I thought were close to me as well, whom my family had fed and dressed when they were in need. Two men I trusted.' ${ }^{2}$ The story unfolds like a play.

Act 1: One day, the two old men invited John to drink kava made from bushes in their garden and prepared by themselves. Kava is a drink made from the roots of a pepper tree. It has sedative and anaesthetic properties. In many communities throughout Vanuatu, kava drinking, usually taking place at sunset, has become an important social time for collective gatherings. John is used to drinking kava every evening. But somehow he felt this invitation was a set-up. He hesitated and finally decided not to join the group. His doubts were confirmed the next day. He says that the two old men were angry that he had not come. They reproached him because they had had to throw away the kava they had prepared. This seemed to have confirmed his suspicions, since 'no one', John says, 'throws away kava just because someone doesn't show up! Something must have been wrong with this kava.'

2 The quotations are translated from Bislama, the pidgin of Vanuatu. 
Act 2: John and his family, like other families in the village, have several gardens. One of these is on the other side of the peninsula, too far away to get there, work and come back the same day. It was in the middle of this garden, which grows yam, taro and cacao, that one day John discovered a plant he had never put into the ground. 'It was a sign', he says. 'Someone had buried something in my garden and planted this shrub on top of it to hide the traces.' Not knowing what to do, he ran home worried. But on arriving in his hamlet, he immediately decided to return to the garden and burn it. While walking up the hill determined to destroy the garden, he felt a strange presence. He stopped, turned around and saw one of the two old men mentioned earlier waiting, hidden behind some trees. Seeing that John had stopped, the old man came forward and said 'days are long, but life is short', John recalls.

Act 3: 'One day, the two old men prepared poison from toxic plants', John explains with assurance. The poison was intended to harm him. 'But one of the two men forgot to wash his hands after preparing it', John claims. In the evening, when drinking kava, he inadvertently dipped one of his fingers into the liquid, poisoned himself and died. The inhabitants of the surrounding hamlets were quick to accuse John of sorcery. Many public meetings took place in which John tried to demonstrate his innocence and convince the community of it. The situation became intolerable and highly conflictual. Only one solution seemed to remain: to leave the village again with his wife and kids and go back to town. The victim had become the suspected aggressor.

However, this would have meant accepting the accusations and leaving as the culprit. This is when John had the idea of calling a Marist priest from another island, a man reputed and feared for his powers. 'You have to pay the priest', John says, 'but when he is here, when he preaches and you are carrying poison with you, you immediately die, so powerful is he.' The priest came and organised a public meeting during which John had to swear on the bible that he possessed no poison and that he had not killed the old man. He publicly and in front of the priest proclaimed his innocence. The same ceremony was repeated during Sunday mass at the mission. 'At this moment', John says, 'many other inhabitants began to fear the consequences of the priest's power. Dozens of them went up to the altar and deposited leaves and cloth in which they had hidden poison.'

Final Act: Before leaving, the priest told John: 'In one year exactly, to the day, something will happen and you will understand who the true culprit is, who has poisoned whom.' 'One year later to the day', John says, 'the other old man, the one who had survived, offered me a cursed apple.' But John did not trust him and refused it, and because he had handled it wrongly, the second old man died as well. According to custom, the body was rolled in mats and buried. But it poured with rain for hours and hours and the tomb filled with water, freeing 
the corpse so that it floated to the surface. Several times the old man's family tried to weigh down the floating body so that it would sink. But the old man kept floating. It was only after many hours that the corpse finally sank under the weight of dirt and mud. 'This was the sign', John says, 'the sign of the deserved punishment'. And John was washed and freed of all accusations and suspicions. It was he who had been the victim.

Let me start the analysis with some general comments. The first point that needs to be made concerns the distinction between sorcery and poisoning. The ethnography shows that sorcery and poisoning follow similar processes and that they are intimately linked to each other in Vanuatu. In the symbolic and rhetoric landscape of south Malekula, both express a specific relationship to the body and the penetration thereof, both aim at destruction and both have an identical relationship with the imaginary that accompanies cannibalism. Moreover, the sorcerer is thought to manipulate poison, and poison is primarily the weapon of a sorcerer. Poisoning does not necessarily have to happen through direct ingestion alone, but can be done from a distance by means of the sorcerer's diverse powers. Hence, while poison is not the only means of action available to the sorcerer, it is certainly a favourite element of his repertoire. Furthermore, people who are accused of dealing in poisons are immediately considered to be sorcerers. In fact, in contrast to Rio (2002), who presents the prototypical form of sorcery in Vanuatu as a process in which the body is emptied and the still living person sent home to die later, I believe poisoning to be the ideal typical and most tangible form of sorcery because it best reflects the articulation of proximity and distance that sorcery seems to be all about in the cases I have encountered. This chapter will hopefully make this point clear. Therefore, sorcery and poisoning are here interchangeable words.

The second general point concerns some of the Christian, and more generally Western, elements reflected in John's recollections. A Marist priest is called and the revelation happens in church, during mass. The punishment endured by the floating body during long-lasting rain and floods, undoubtedly recalling Noah's story, points to Christian and more generally Western (the 'poisoned apple') themes of interpretation that have been studied by Eriksen (2008), for example. That there is a degree of syncretism in contemporary sorcery is beyond doubt, but also beyond the scope of this chapter. Here we will rather deal with the conditions of emergence and expression of sorcery accusations as reflecting changing configurations of being. Having established these two preliminary points, let me now turn to depicting the historical and cultural background to John's account. 
Talking it Through

\section{Sorcery as a consequence of historical conditions}

John and his family live in an area of great historical disturbances. The peninsula of Port Sandwich, located in the south-east of Malekula Island, was once split between three clans, according to one version of local history: the Pnoamb, the Lambru and the Bangu. Each clan (people call them 'tribes') occupied and owned a territory extending across the peninsula and parallel to that of its neighbouring group, thus providing each of them with access to both the coast with its marine resources and the inland hills where gardens were cultivated. Although the villages are now exclusively situated along the coast, they were formerly also established in the hinterland, in the hills, and families seem to have practised some degree of movement between the inland hamlets and those along the coast.

Groups of brothers, the eldest of these often playing the role of head of the clan, distributed plots of land to individual families for their gardens. All of these families still have today several gardens at unequal distances from the hamlets in cleared and burned forest areas. People mainly grow taro, yams and bananas; now also tomatoes, cabbage, cassava, peanuts, lettuce and even strawberries. The soil is fertile, especially when winds carry volcanic ashes from eruptions on nearby islands. But the soil is also shallow and rotation of the gardens is a necessity. The pressure on land is thus not evaluated only in terms of the surface immediately accessible but includes the capacity to access land in coming years.

These clans, like other groups in southern Malekula such as the people of Southwest Bay studied by Deacon (1934), are characterised by a strong patrilineal ideology. Each patrilineal clan, sometimes divided into lineages, consisted of several hamlets that were the owners of an identifiable and bounded territory. These various hamlets were associated with a main village established by the clan's ancestor. This central hamlet, the heart of the clan, hosted the ritual site (called nasara) in which an important element was the men's house (batu). The batu housed the clan's sacred objects, for example, the skulls of deceased ancestors that had not yet undergone the second funerals (cf. Guideri and Pellizzi 1981; Huchet 1976; Servy et al. 2012). The men's house was divided into several sectors reflecting the religious and political ranks or grades of the men. The young initiates slept at the entrance, while the bottom of the batu could only be occupied by namals, the most senior and advanced ritual chiefs. Namals were considered to be almost spiritual beings able to transcend 'natural' and 'human' boundaries. They were also feared sorcerers and, for some at least, renowned cannibals, so people say. It is important to note that clan chiefs or elders - the landowners - were not necessarily also ritual and ranked chiefs, 
namals. The latter could be (and some say that they even were systematically) people from other groups and tribes, foreigners gaining access to power through the sacrifice and redistribution of pigs.

As already alluded to, inhabitants of the peninsula espouse several versions of the local history (see Dousset n.d. b). Most likely however, before the strong presence of the colonial powers, the peninsula was inhabited and owned by the three clans mentioned. They were linked through close religious, political and kinship ties. The kinship terminology and marriage rules were oblique and are thus evidence for the existence of these three groups and their organic interrelationship, since oblique marriages necessitate triangular relationships between groups (Dousset n.d. a).

The first white settlers arrived in Port Sandwich in 1884 and missionaries in 1890. These events severely disrupted the political and demographic situation of the peninsula. In the political domain, this was because missionaries struggled against the graded chiefs, who exercised their power in the religious sphere and used sorcery and cannibalism as a means to consolidate their authority. As might have been expected, the missionaries and settlers favoured negotiations with clan chiefs, who were the landowners and had authority in everyday affairs. The arrival of white settlers also had important demographic consequences, since their usurpation of land - often in return for a handful of tobacco or a gun and the presence of new tools and goods as well as Christianity and the hope for pacification had significant effects on migration. Linguistic and ethnographic data, as well as ethnohistorical narratives and myths, reflects previous strong migratory pressures that increased significantly with the arrival of the Marists. Many groups from the interior of Malekula Island gradually moved to the coastal regions of the peninsula.

The period between 1884 and 1920 was hence a period of considerable disruption, conflict and adjustment between Melanesian groups who had to learn to live together and between Melanesians and white settlers. The situation culminated in 1920 with a new era, when the French colonial delegation was installed in Port Sandwich and when mass baptisms of the local population were organised. The strong foreign presence increasingly undermined all forms of indigenous power, not just that of the graded chiefs and namals as in former times, and resulted in the weakening of the authority of clan chiefs and landowners. The Melanesian hierarchies were being levelled out.

Like the later events of 1980, the year of Vanuatu's independence, the arrival of the French administration in 1920 is described by locals as having led to substantial change. Tensions and conflicts between families and clans were replaced by what they describe as a period of new social construction, with a sense of belonging to a new collective project. Port Sandwich was the new France 
in the New Hebrides, with its school, hospital and administrative services. It was a time, people stress, when everyone had work, when roads were built and kept clean, when the centre of the village was lit at night, when order reigned and when sorcery and cannibalism had disappeared. Port Sandwich was to become a new society in which former hierarchies had disappeared. Under the control of the French administration, the Melanesians became equal among themselves. What appears to be a situation idealised by the vast majority of the approximately 1,500 inhabitants of Port Sandwich (at least by the population that had actually experienced the presence of the French authorities before 1980) abruptly changed at the time of independence. Here we must again make a historical detour to better understand how, in the eyes of the population, this idealised society ended with independence, despite the colonisers leaving and handing back at least part of the land to the Melanesians.

The movement for the independence of Vanuatu was led by two important Melanesian figures, Father Walter Lini, anglophone and Presbyterian, and Father Gérard Leymang, francophone and Marist. Walter Lini was the main leader, and he and his friend Gérard Leymang both occupied in turn the position of prime minister, preparing for independence and drafting the future constitution of the independent state. Together, they led the National Party. However, shortly before independence, the two friends separated and adopted deeply contrasting perspectives. Lini announced his 'one country, one language, one religion' slogan, implying that the national language was to be Bislama, the pidgin of Vanuatu, and the national religion Protestantism. Leymang could not accept this statement and created his own party, the Union of Communities of the New Hebrides (UCNH), which later became the Union of Moderate Parties. It attracted mainly francophone Catholics. Lini, meanwhile, founded the Vanua'aku party with predominantly anglophone Protestants as members. The fundamental difference between these two parties was both simple and a source of conflict the Vanua'aku party and Walter Lini demanded immediate independence, while the UCNH and Gérard Leymang wanted autonomy first and independence only at a later stage.

Let me now return to Port Sandwich. The UCNH party was well established in the peninsula. Indeed, Father Leymang was born in Port Sandwich, where his family still lives today. The peninsula had thus become the bastion of autonomy and was seen by Lini and his people as a place of betrayal of and rebellion against independence. On the day of independence, Papuan and Ni-Vanuatu troops, assisted by an Australian infrastructure, came to plunder the facilities of Port Sandwich and arrested the vast majority of its adult male population, some of whom were to be imprisoned for several months on Santo Island. In the eyes of the inhabitants of Port Sandwich, independence had thus become a nightmare and reminded them of humiliation and denigration and the loss of 
all benefits and privileges. Independence had become the word for all evil and eventually stigmatised the nascent state itself and its dysfunctions. Expensive education and health services, corruption and poverty were, and for some still are, seen as the consequences of a badly prepared independence movement. More importantly, however, the apparent equality among Melanesians that had been instituted by the French colonial power was crumbling. Internal hierarchies again emerged, with some clans and their leaders claiming to be the original inhabitants and landowners, descendants of the three original clans, and reducing others to being 'man-come', foreigners and invaders. There was again a big upsurge in accusations of sorcery.

\section{Questions concerning the re-emergence of sorcery}

With the arrival of missionaries and plantations owned by white settlers, other groups gradually, but massively, migrated towards the peninsula and settled in the area, as I mentioned earlier. While three nasara (a clan's ritual place including semi-buried stones that symbolise the clan's ancestors) seem to have existed on the peninsula before the missionaries arrived, today more than 20 are claimed to be there. Demographic pressure became a problem and landownership a disputed concept. The pacification of intergroup conflicts and the levelling of indigenous hierarchies by the colonial administration, as well as intermarriages, exchanges and the shared experience of colonial history that followed the migration of many groups to the coast, blurred the peripheries of the clans and was at the origin of a more uniform social landscape. The issue became crucial after independence, with the necessity and desire to identify traditional landowners once again. The question was and still is today: which families are the descendants of the peninsula's 'original' inhabitants, and what are their social and spatial boundaries?

These discussions and conflicts are accompanied by an increase in the perception of sorcery attempts. The reasons for this are the new means of accumulating wealth and of displaying it, which have consequences on the control of social values, as Eves (2000) has also shown for the Lelet. But the apparent increase in sorcery is also a result of the previously blurred peripheries of clans and domestic units during the colonial period. The haziness of these peripheries had to some extent been a useful means for establishing a oneness against other more distant Melanesian groups and white settlers. In the postcolonial context, however, internal divisions and boundaries have to be re-established and in some cases reconstructed. This is so because the demographic pressure on land is considered too high, but also because there is an increasing attitude 
of segregation and differentiation between people who consider themselves to be locals and who therefore consider others to be foreigners. Accusations of sorcery are among the tangible expressions of the attempts - and the rejections thereof - to re-establish social entities and hierarchies. In this context, one may ask whether it is not indeed in John's interest to be a victim of sorcery attempts? Does this not confirm him and his clan as arousing jealousy and thus as being 'authentic', descendants of one of the three original clans? Otherwise why would people try to eradicate him and his family? Let us attempt to answer these questions in more detail.

After independence, it is said, there was an impressive increase in cases of poisoning and sorcery in general - or at least in accusations of sorcery - in south Malekula, as elsewhere in Vanuatu and in many postcolonial situations. Some researchers link the phenomenon to a context of political insecurity and instability in which authority and its forms are questioned, in which new and old systems of power confront each other and in which new kinds of economic inequality emerge. For these researchers, sorcery is predominantly a thing of modernity. Because of its intrinsic link to the state, nation building and the emergence of a capitalist economy, many authors have analysed the complex relationship between sorcery, state governance and legislation (for example, and of course first and foremost, Comaroff and Comaroff 1993, and Geschiere 1988 for Africa; for Vanuatu, Forsyth 2006; Rio 2010; Rodman 1993 etc.).

Others have had more universalistic or cross-cultural approaches and seen in sorcery the necessary process of identifying the intentionality of social disruption in general (e.g. Clément 2003) and a way to perceive and interact with the invisible (Bonhomme 2005), or a means of deflecting grief on the death of a loved one towards an external figure (Stephen 1999). Still others, but again in a cross-cultural spirit, see in sorcery and magic a kind of religious behaviour, a form of communication promoting or protecting cooperative social relationships, in the case of sorcery, through threat and fear (e.g. Palmer et al. 2010).

In these latter approaches, sorcery is not tied to modernity as such but is a quasi-universal and not necessarily historically situated phenomenon because, as Bonhomme (2005:271) writes for Africa, 'modernity and tradition designate ... not so much heterogeneous temporalities as different scales that coexist and are interconnected' (my translation). We have indeed seen above that sorcery was a means to regulate power even before the arrival of the colonial powers and the state and that it was a means in the hands of the namals, the ritual chiefs.

In most of these studies, be it from a historical, political and legal perspective or from a cognitive, psychoanalytical and cross-cultural one, sorcery is seen as a correlative of unstable and disruptive situations or as producing such situations, 
if not both at the same time. I would like to suggest that we could also turn the problem upside down. Accusations of sorcery are of course stressful and sometimes result in harm and even executions. What I would like to explore is how what seems to matter in the cases I have analysed is the answers to the following question: how come those who are suspected of sorcery are not complete foreigners, not unknown people, but are often (if not always) relatively close kin (or potentially close kin), people one has fed and protected, as John says, or people one could marry? How come the danger of sorcery comes from the immediate periphery?

One of the central points made here has been aptly put by Bloch (1998) and relates to the notions of commensality and consubstantiality, ${ }^{3}$ even though I would like to go somewhat further. He writes:

the Zafimaniry are as obsessed by the theme of poisoning as they are by the theme of domestic oneness. In reality, for them, the two are different sides of the same coin. (Bloch 1998:144)

Geschiere (1995:18) and Bonhomme (2005:259) have made similar statements for Africa. For the former, even in modern contexts, sorcery remains linked to the intimacy of the family. For the latter, sorcery articulates explanations of misfortune and the expression of conflicts within the lineage group. Sorcery is something local, not necessarily global. And it is so local that it seems to be intimately tied to values (see Eves 2000), the family or domestic unit and changes therein.

Inquiring into what are, among the Zafimaniry, the vehicles for the strong domestic unit ideology, Bloch (1998:135) defines commensality as the action of eating together and as one of the most powerful operators of social process. He talks of food as being a social conductor whose purpose is to reinforce or establish a shared substance. By recalling Durkheim's notion of organic solidarity, he explains how sharing food from the same animal or eating and drinking from the same bowl ${ }^{4}$ is among the strongest social conductors. 'In many cultures', he writes, 'the sharing of meat is a sign of supreme closeness ... which makes meat eating particularly suitable for feasts and celebrations' (ibid.). ${ }^{5}$ Sharing food expresses and causes bodily unification, quite similar to that of kinship and marriage (Bloch 1998:137). We may also recall here the work of Lévi-Strauss (1968), among many others, on the relationship between eating and sexuality.

\footnotetext{
3 Also see Pitt-Rivers $(1973)$ and Dousset $(2005,2013)$ for use of the notion of 'consubstantiality' in other but comparable contexts.

4 As opposed to eating separate pieces of different origins, which would be mechanical solidarity.

5 Also see Bonhomme (2005:261, note 4) for Gabon, who writes that sorcery is based on animal predation with the victim being the meat for the sorcerer who is represented as a panther.
} 
Eating the same food unites bodies, eating different food distances bodies, Bloch explains, and Zafimaniry families strive to be continually unified by biology or kinship and as commensal units.

Although important, this is obviously a very general statement. Indeed, we may recall the work of Carsten (1997) who explains that for Malays being one family or kinship group cannot be envisaged in terms that do not, in part, refer to the act of eating what has been cooked on one hearth (quoted in Bloch 1998:139). Or I might add an example from the Australian Western Desert where the word designating the adopting mother also means the one who maintains the hearth on which food is cooked. Joining a family is about becoming consubstantial to the latter through the consumption of its food (Dousset 2011).

The relationship between eating and belonging has been widely documented and discussed. What is relevant for our concern here is that, like sexual relations or marriage, sharing food is an act that belongs to the mapping of social space through the redefinition of who sits in the inner circle, and for what reason, and who is outside; it is about the definition of proximity and distance, of self and stranger. Commensality, Bloch (1998:146) writes, is 'a means by which the domestic house unit can be adventurously expanded' (see also Munn 1986:13).

But this is not without risks, because 'the better a food is a conductor that creates bodily closeness, the better it is a medium for poison' (Bloch 1998:145). Interestingly, among the Zafimaniry, Bloch cites the drinking and sharing of rum (and we can think of kava as a similar medium in Vanuatu, as John's story testifies) as being the best conductor and thus also the best vehicle for poisoning, because it is a medium of and for social equality. Differences and shame or restraint are temporarily neutralised. Here I quote Bloch for the last time:

the risks involved in eating are normally neutralized by eating with those one knows well. If one has to, or wants to, eat with distant others, however, it is normal that the fear of poisoning should increase, and, as a result, the willingness to overcome that fear becomes proof of a commitment that is continually being bargained about in the process of establishing moral social links. (Bloch 1998:147)

What can we learn from this? First, poison takes the same path as the social processes that confirm, reinforce or expand the domestic unit, those with whom one shares relatedness through commensality. This recalls another account I was given in the field, in which a man explained to me that sorcery 'arrives always from where you don't expect it, from family you trust and who share food or kava with you'. Sorcery is the invisible agent for the refusal of sameness and for both the usage and denial of the powers of commensality. It is the 'obscure underside of kinship' (Bonhomme 2005:265). 
Second, when poison, or sorcery in general, comes into play, the boundaries - how permeable they are - of the circle of social confidence, of 'natural' trust, are questioned and remodelled. This happens when 'almost outsiders' are to be made members of the domestic oneness, when the boundaries are either expanded or retracted. I can again quote the same man, a self-declared magician and healer, when he added that 'the danger comes from your family ... but not your actual parents or children or brothers; it comes from nephews, cousins, in-laws ... who have been convinced and paid to do it'. These are people who are not unambiguously part of one's inner circle. They are those with whom oneness does not flow automatically, so to speak, but has to be acquired through sexuality, marriage and reciprocity. They are at the periphery; they are the periphery. Just like food, they themselves work as connectors to other lineages and domestic groups. They are potentially the obscure underside of kinship just as poison is the obscure underside of food. No wonder, one is tempted to state bluntly, there is a recrudescence in accusations of sorcery in postcolonial Port Sandwich with the boundaries, and therefore the peripheries, of social circles being reconstructed, remodelled and questioned.

\section{The 'traditional' sorcerer, clan politics and humanity}

There is another point that needs to be made, briefly at least, that was also addressed by Forsyth (2006): the 'generalisation' of sorcery and its subsequent loss of public legitimacy. In the south of Malekula, as was mentioned earlier, there were two parallel power structures that seem to have overlapped but only to a certain extent. The first was situated in the clan itself and in its chief. He was the guardian of the land and of the kin group's continuity. While it was not impossible for this kind of chief to also be a magician or even a sorcerer, the latter would not usually be part of his repertoire. The second power structure, on the other hand, resided in the system of graded chiefs, a process in which men and women could take part through the organisation of rituals that included the sacrifice of large amounts of pigs (see Guérard 1994). Ritual after ritual and grade after grade, these chiefs would move further away from being merely humans and progressively become spirit-like beings. As already mentioned, the highest of these grades, just before becoming an actual spirit, was that of the namal. Namals were feared for their magical powers and for their capacity to take on, like any sorcerer, a morphology different from that of the human being. They were also said to have been allowed to practise or to have practised cannibalism. A namal, or for that matter any graded chief, does not also have to be a local clan chief. Many are indeed reported to have been individual migrants from other groups who were adopted into local clans. Thus, while they were seen 
to be able to cross the borders between humanity and the supernatural, they were also at the periphery of the social group which had adopted them: foreigners but not unknown, people who married in, people with whom one shares things, in particular food, but not without some fear and hesitation, people who may eat those who feed them. The last namal of the Port Sandwich peninsula, who was killed by the French authorities in the 1920s, is said to have made extensive use of his cannibalistic rights and demanded the sacrifice of the other clans' masculine descendants. He thus directly interfered, through the sacrifice of the boys and sorcery, in other clans' capacity to reproduce themselves as a social unit.

Still today in Port Sandwich, the image of the sorcerer points towards features and capacities that, like those of the namals who no longer exist in Port Sandwich, sit on the blurred periphery of humanity. Indeed, people's accounts make it possible to paint a picture of the presumed sorcerer defined by three main characteristics: a changing morphology, unsocial attitudes, and destructive means of action.

\section{Morphology}

The sorcerer is considered to be a recognisable human. He may indeed be living in the midst of others. However, because of his ability to communicate with natural species and spirits and to handle dangerous human and non-human substances, his morphology is not permanent. He can even turn into an invisible creature. He may appear as a shark, as a bat, or as an insect flying in the twilight. The sorcerer has a changing morphology, he travels and works at night or in the dark and is not effortlessly noticeable: the shark coming from the depths that suddenly attacks at the surface, or the insect or bat that stings or bites humans in the evening or at night to inject its fatal substances. His behaviour is the opposite to that expected from humans whose movements are supposed to be predictable and visible.

\section{Social attitude}

In most accounts, the sorcerer is thought to be socially disinterested, if not dissocialised. He may not necessarily act of his own initiative, but may do so on behalf of another person who rewards him for his services. He thus has no compassion and is a ruthless professional. While those who may ask for the sorcerer's services are known kinsmen, the sorcerer himself remains voluntarily outside kinship. This is either because he no longer obeys the obligations associated with kinship or has become emotionally distanced, or because he is a foreigner who has forgotten or not yet been included into the local family or marital history. The sorcerer withdraws into the hills, into the bush, living on his own, eating little or not at all, respecting sexual abstinence, and avoiding contact with other human beings. 


\section{Means of action}

The sorcerer has various modes of action to harm and destroy, but two modes are prototypical: body-draining is the typical form of sorcery according to Rio (2002), who worked on the island of Ambrym. Direct or remote poisoning is, in my opinion, the prototypical form of sorcery in Malekula, even though both types of action are thought to have existed formerly on the two islands. When body-draining, the sorcerer attracts his victim, kills them in one way or another (usually through poisoning or strangulation), empties the body and fills it up with plants. He then sews it back together and sends the victim home to die, alive but with no memory of what has happened.

Poisoning may take several forms. It can be done remotely or by physical ingestion of toxic substances. Potions are composed of plant substances and human parts: bones, blood or guts. The poison is thought to burn and destroy the body from the inside. In both cases, whether it takes place from a distance or through actual ingestion, penetration of the body is required. This penetration has to be undertaken through the use of powerful and dangerous substances, including those that are prohibited and even taboo, such as the blood and liquids of corpses. Conversely, non-sorcerers value cooked food eaten in common. Eating together, sharing a meal or kava are highly valued and define what it is to be a human being.

These images and elements that define the sorcerer, and for that matter also the namals, stand at the periphery of humanity or even reflect the opposite of the ideal typical conception of a human. The sorcerer is unpredictable, morphologically unstable, a known foreigner, a loner and a dissocialised individual valuing sexual abstinence, destruction and contagion. The ideal typical human being, on the other hand, is expected to be predictable and morphologically stable, to be a kinsman living collectively and socially and valuing abundance, reproduction, constructive attitudes and consubstantiality.

\section{Conclusion}

There are theories or suggestions that attempt to explain sorcery as a universal phenomenon. These approaches are often cognitive or psychoanalytical. And there are approaches that frame sorcery as a product of local cultural systems and historical conditions. This chapter has attempted to combine a cross-cultural with a contextual approach.

The cross-cultural aspects are those that link sorcery to the attempts of social groups to reproduce themselves in time and space through commensality. Sorcery, and in particular poison, as well as cannibalism, makes use of the same 
channels as humanity and its endeavour to become consubstantial, but has exactly the opposite ambition: to blur and weaken this commensality by eating or destroying those who eat and live together. If sorcery is the place where boundaries and institutions are reshaped, where being is redefined, it is not so surprising that sorcerers are in many cultures reported to also have cannibalistic and antisocial attitudes, as Needham (1978) has already pointed out.

John's story could have been looked at from various perspectives, such as through the Christian symbolism deployed. From the local historical perspective, I have approached the particular situation through the idea that sorcery is intimately tied to three elements. First, the definition and transformation of what is locally a social unit of commensality and how its boundaries are or have been shaped and reshaped by historical processes. Second, the idea that accusations and counter-accusations of sorcery are obviously embedded in local politics, in particular those politics which involve discussions on 'authenticity' and the primacy of culture and landownership, and those aspects of self-positioning that define belonging expressed through mutual trust or lack of it. Third, in certain contexts, being in danger of becoming the victim of sorcery provides proof of someone else's jealousy and one's own importance and rightfulness in the context of the abovementioned historical processes.

However, from the cross-cultural perspective, as Delpech-Ramey (2010) explains when discussing Guattari and Deleuze, sorcery is the condensed ability to 'go beyond' the normal place of development. It is the sign of and the means for shifting boundaries and institutions in general. It is the place where distinctions and similarities between animality and humanity are redefined and where the legitimacy of power is questioned. It is suggested that these are the universal aspects of sorcery. The local historical aspects are only those from which and on which sorcery works and acts.

\section{References}

Adorno, T. 2005. Minima Moralia: Reflections on a Damaged Life [Minima Moralia: Reflexionen aus dem Beschädigten Leben]. London: Verso.

Bloch, M. 1998. Commensality and Poisoning. Social Research 66(1):133-49.

Bonhomme, J. 2005. Voir Par-Derrière. Sorcellerie, Initiation et Perception au Gabon. Social Anthropology 13(3):259-73.

Clément, F. 2003. L'esprit Ensorcelé. Terrain 41:121-36.

Comaroff, J. and J.L. Comaroff (eds.) 1993. Modernity and its Malcontents: Ritual and Power in Postcolonial Africa. Chicago: Chicago University Press. 
Deacon, A.B. 1934. Malekula: A Vanishing People in the New Hebrides. London: George Routledge \& Sons.

Deleuze, G. and F. Guattari 1983. Anti-Oedipus [L'anti-Oedipe]. Minneapolis: University of Minnesota Press [1972].

Deleuze, G. and F. Guattari 1987. A Thousand Plateaus [Mille Plateaux]. Minneapolis: University of Minnesota Press [1980].

Delpech-Ramey, J. 2010. Deleuze, Guattari, and the 'Politics of Sorcery'. SubStance 39(1):8-23.

Dousset, L. 2005. Structure and Substance: Combining 'Classic' and 'Modern' Kinship Studies in the Australian Western Desert. TAJA: The Australian Journal of Anthropology 16(1):18-30.

Dousset, L. 2011. Australian Aboriginal Kinship: An Introductory Handbook with Particular Emphasis on the Western Desert. Marseille: Pacific-Credo Publications.

Dousset, L. 2013. From Consanguinity to Consubstantiality: Julian Pitt-Rivers' 'The Kith and the Kin'. Structure and Dynamics: eJournal of Anthropological and Related Sciences. 6(1). http://www.escholarship.org/uc/item/4fr203tx.

Dousset, L. n.d. a. Parenté, Territoire et Démographie. In M. Jeudy-Ballini (ed.) Mélanges. Press unknown.

Dousset, L. n.d. b. Rupture et Continuité dans le Sud de Malekula. In E. Nolet and P. Lindenmann (eds). Logiques Locales, Logiques Nationales en Mélanésie. Paris: Société des Océanistes.

Eriksen, A. 2008. Gender, Christianity and Change in Vanuatu: An Analysis of Social Movements in North Ambrym. Burlington: Ashgate.

Eves, R. 2000. Sorcery's the Curse: Modernity, Envy and the Flow of Sociality in a Melanesian Society. Journal of the Royal Anthropological Institute 6(3):453-68.

Forsyth, M. 2006. Sorcery and the Criminal Law in Vanuatu. Lawasia Journal 1:1-27.

Geschiere, P. 1988. Sorcery and the State: Popular Modes of Action among the Maka of Southeast Cameroon. Critique of Anthropology 8:35-63.

Geschiere, P. 1995. Sorcellerie et Politique en Afrique. La Viande des Autres. Paris: Karthala.

Guerard, C. 1994. Mana et Pouvoir dans les Sociétés à Hiérarchie de Grades (Vanuatu). Archives des Science Sociales des Religions 85:153-74. 
Guideri, R. and F. Pellizzi 1981. Shadows: Nineteen Tableaux on the Cult of the Dead in Malekula, Eastern Melanesia. RES: Anthropology and Aesthetics 2:5-69.

Huchet, C. 1976. Fête Funéraire à Lendombwey (Centre-Sud Malekula) 'Netemstamp' (Septembre 1974). Journal de la Société des Océanistes 32(53):293-8.

Lévi-Strauss, C. 1968. Mythologiques III. L'origine des Manières de Table. Paris: Plon.

Lindenbaum, S. 1981. Images of the Sorcerer in Papua New Guinea. In M. Zelenietz and S. Lindenbaum (eds.) Sorcery and Social Change in Melanesia. Social Analysis No. 8 (Special Issue). Adelaide: University of Adelaide, 119-28.

Munn, N.D. 1986. The Fame of Gawa: A Symbolic Study of Value Transformation in a Massim (Papua New Guinea) Society. Cambridge: Cambridge University Press.

Needham, R. 1978. Primordial Characters. Charlottesville: University of Virginia Press.

Owen, A. 2004. The Place of Enchantment: British Occultism and the Culture of the Modern. Chicago: Chicago University Press.

Palmer, C.T., L.B. Steadman, C. Cassidy and K. Coe 2010. The Importance of Magic to Social Relationships. Zygon 45(2):317-37.

Pitt-Rivers, J. 1973. The Kith and the Kin. In J.R. Goody (ed.) The Character of Kinship. Cambridge: Cambridge University Press, 89-105.

Rio, K. 2002. The Sorcerer as an Absented Third Person: Formations of Fear and Anger in Vanuatu. Social Analysis 46(3):129-54.

Rio, K. 2010. Handling Sorcery in a State System of Law: Magic, Violence and Kastom in Vanuatu. Oceania 80(2):183-97.

Rodman, W. 1993. Sorcery and the Silencing of Chiefs: 'Words on the Wind' in Postindependence Ambae. Journal of Anthropological Research 49(3):217-35.

Servy, A., M. Abong and L. Dousset 2012. Funérailles à Malekula, Vanuatu. Catalogue Augmenté et Documenté de L'exposition Photographique 'Georges Liotard (1974)'. Marseille: CREDO and VKS.

Stephen, M. 1999. Witchcraft, Grief and the Ambivalence of Emotions. American Ethnologist 26(3):711-37. 
Zelenietz, M. 1981. Sorcery and Social Change: An Introduction. In M. Zelenietz and S. Lindenbaum (eds). Sorcery and Social Change in Melanesia. Social Analysis No. 8 (Special Issue). Adelaide: University of Adelaide, 3-14.

Zelenietz, M. and S. Lindenbaum (eds.) 1981. Sorcery and Social Change in Melanesia. Social Analysis No. 8 (Special Issue). Adelaide: University of Adelaide. 
This text is taken from Talking it Through: Responses to Sorcery and Witchcraft Beliefs and Practices in Melanesia, edited by Miranda Forsyth and Richard Eves, published 2015 by ANU Press, The Australian National University, Canberra, Australia. 